\title{
TÉCNICAS DE NUCLEAÇÃO COMO ESTRATÉGIA DE RECUPERAÇÃO E VALORAÇÃO AMBIENTAL DE ÁREAS DEGRADADAS SITUADAS NO ALTO RIO SÃO LOURENÇO, CAMPO VERDE-MT
}

DALTRO, Renata Freitag. Bióloga. Mestranda em Recursos Hídricos - UFMT. E-mail: renatafreitag2@yahoo.com.br.

SILVA, Normandes Matos da. Professor no Curso de Engenharia Agrícola e Ambiental - CUR/UFMT.

E-mail: normandes@ufmt.br.

VECCHIATO, Antônio Brandt. Professor no Departamento de Geologia - ICET/UFMT. E-mail: brandt@ufmt.br.

\begin{abstract}
Resumo
Buscou-se avaliar a eficiência das diferentes técnicas que compõem o plano de recuperação de área degradada (PRAD) em uma das cabeceiras do rio São Lourenço, Campo Verde-MT, a partir do monitoramento da fase inicial da regeneração vegetal de áreas de preservação permanente degradadas, de acordo com a Lei Federal 4.771/65 e suas atualizações. Aárea experimental foi dividida em cinco tratamentos, onde ocorreu o plantio de mudas nativas, frutíferas, leguminosas, adubação verde e muvuca de sementes, tendo como princípio os preceitos da nucleação. Para cada tratamento houve a seleção aleatória de três parcelas, medindo 81m2, totalizando 12 parcelas. Nessas parcelas ocorreu o acompanhamento do plantio, identificação e caracterização dos indicadores de regeneração da cobertura vegetal local. Os indicadores encontrados no local foram: flores, frutose sementes das espécies revegetadas; vestígios e presença da fauna; produção de serapilheira e cobertura vegetal do solo; e formação de microclimas, com aumento da umidade relativa do ar e diminuição da temperatura atmosférica.
\end{abstract}

Palavras-chave: Técnicas nucleadoras; Vegetação; Muvuca de sementes.

NUCLEATION TECHNIQUES AS A STRATEGY FOR RECOVERY AND ENVIRONMENTAL VALUATION OF DEGRADED AREAS located in alto Rio São Lourenço, Campo Verde-MT

\begin{abstract}
Our aim was to assess the effectiveness of different techniques that comprise the recovery plan of degraded area (RPDA) in one of the headwaters of São Lourenço River, Campo Verde-MT, by monitoring the early stage of plant regeneration of permanent preservation degraded areas, according to the Federal Law 4.771/65 and its updates. The experimental area was divided into five treatments, for the planting of native plants, fruit, legumes, green manure and muvuca seed, based on the precepts of nucleation. For each treatment there was a random selection of three installments, measuring $81 \mathrm{~m} 2$, totaling 12 plots. The planting, the identification and the characterization of indicators of vegetation regeneration site were monitored in these plots. The indicators found at the site were: flowers, fruits and seeds of revegetated species; traces and presence of wildlife; litter production and soil cover, and formation of microclimates, with increasing relative humidity and decreased atmospheric temperature.
\end{abstract}

KEYwORDS: Nucleation techniques; Vegetation; Muvuca see. 


\section{INTRODUÇÃO}

Em termos de potencial de recursos hídricos, o Brasil possui a maior disponibilidade hídrica do planeta, ou seja, 13,8\% do deflúvio médio mundial (ANA, 2009), sendo, o Estado de Mato Grosso o maior divisor de águas da América do Sul, pois separa parte das duas maiores bacias hidrográficas do Brasil, a Amazônica e a Platina. Além disso, a bacia do Tocantins possui em terras mato-grossenses o seu principal tributário, o rio Araguaia (PERH, 2009).

No entanto, o modelo de desenvolvimento implantado na região, segundo Martins (2010), é o de substituição das florestas nativas pelo plantio de monocultura mecanizada e pastagens. A ocupação de cabeceiras de drenageme a destruição de matas ciliares em decorrência das atividades agropecuárias é um padrão comum observado no Estado (SALOMÃO et al., 2007).

Nesse contexto, está inserida a bacia hidrográfica do rio São Lourenço, localizada no município de Campo Verde, sudeste de Mato Grosso, sendo a unidade de planejamento e gestão (UPG) de código P5, apresentando os maiores níveis de criticidade $(72,5)$, com grande potencial de ocorrer problemas com os recursos hídricos e é definida como de alta prioridade de intervenções (SEMA, 2009).

As cabeceiras do São Lourenço ocupam 750 mil hectares, e abrangem sete municípios do Estado de Mato Grosso: Campo Verde, Dom Aquino, Jaciara, Juscimeira, São Pedro da Cipa, Poxoréo e Rondonópolis (CAMPO VERDE, 2011).

Estudos realizados na bacia do rio São Lourenço, por Possavatz (2010), demonstraram que a mobilidade dos pesticidas por escoamento superficial, lixiviação e volatilização é fator determinante na contaminação do aquífero freático. Casara (2011) detectou diversos pesticidas tanto "em amostras de água superficial e subterrânea como sedimento de fundo, mostrando a vulnerabilidade da área de cabeceira de drenagem do Rio São Lourenço à contaminação".

Lima (2012) constatou a regressão de uma das nascentes do rio São Lourenço em direção à parte mais baixa do terreno. Checoli (2012) trabalhou com gestão participativa da microbacia hidrográfica na cabeceira do rio São Lourenço, visando à definição e implantação de diferentes técnicas relacionadas ao plano de recuperação de área degradada (PRAD).

Mato Grosso possui área aproximada de 90 milhões de hectares e, de acordo com Azevedo e Saito (2013), $70 \%$ da área potencialmente ocupada por propriedades rurais no Estado não possuía regularização até o ano de 2006. Nesse cenário, em 2009, a Secretaria de Estado do Meio Ambiente de Mato Grosso (SEMAMT) detectou cerca de 1.230.000 hectares de matas ciliares e cerca de 100 mil hectares de reservas legais degradadas no Estado (SEMA, 2011). O instrumento utilizado por órgãos ambientais de fiscalização, para regularização de áreas degradadas situadas em ambientes protegidos, tais como a área de preservação permanente e reserva legal, é o Plano de Recuperação de Área Degradada (PRAD). Do PRAD consta, dentre outras informações, informações acerca das técnicas de revegetação utilizadas.

A presente pesquisa avaliou a eficácia de diferentes técnicas utilizadas para viabilizar o plano de recuperação de área degradada em uma das cabeceiras do rio São Lourenço, no intuito de avaliar a viabilidade do uso dos princípios de nucleação.

\section{MATERIAL e MÉtodos}

\section{Área de Estudo}

O município de Campo Verde (Figura 1) está situado na região sudeste do Estado de Mato Grosso, a $130 \mathrm{~km}$ da capital Cuiabá. Possui uma área de $4.782,116 \mathrm{~km}^{2}$, com população de 31.589 habitantes (IBGE, 2011). A média anual de precipitação é de 1.398mm (CAMPO VERDE, 2011).

A economia do município de Campo Verde gira em torno da agricultura, pecuária, indústria, comércio e construção civil. O seu crescimento econômico está acima da média nacional, com Produto Interno Bruto (PIB) municipal em torno de 512 milhões em 2005, ocupando a 7. ${ }^{\mathrm{a}}$ posição no Ranking Econômico de Mato Grosso (IBGE, 2011).

A área de estudo (UTM 694000 - E / 827000 - N e 706000 - E / 8284000 - N) deste projeto está 
localizada em uma das nascentes do Rio São Lourenço-MT. A vegetação remanescente é característica da fitofisionomia de cerrado do tipo Campo Cerrado (Savana Parque), apresentando árvores com troncos e galhos retorcidos com casca grossa, folhas coriáceas e pilosas, sendo protegida por cortiça, constituindo um sistema intermediário entre o cerrado e a pastagem (SILVEIRA, 2002).

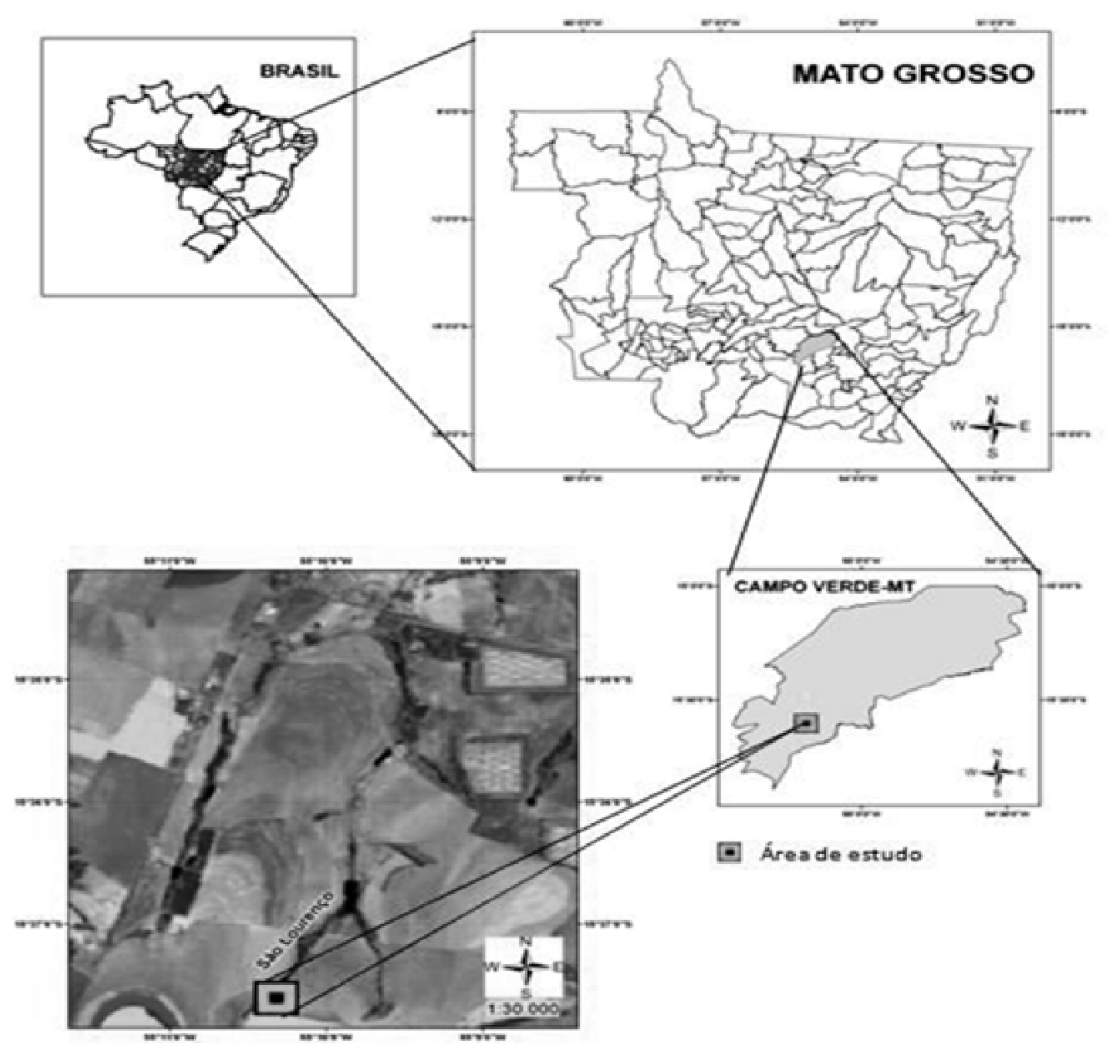

Figura 1 - Contextualização Geográfica da Área de Estudo.

Fonte: Pietro-Souza et al. (2012).

\section{Metodologia}

A área experimental monitorada foi revegetada por meio da muvuca de sementes (mistura contendo diversas espécies nativas de diferentes grupos ecológicos) e da adubação verde (espécies leguminosas exóticas não invasoras de ciclo curto). O plantio foi realizado em núcleos de diversidade, compondo cinco tratamentos. Em cada um dos cinco tratamentos foram realizadas diferentes técnicas de plantio (Quadro1). 


\begin{tabular}{|c|c|c|}
\hline Tratamentos & Área & Tecnologia \\
\hline $\mathrm{T} 1$ & Cabeceira $-0,89$ ha & Isolamento \\
\hline $\mathrm{T} 2$ & $\begin{array}{l}\text { Margem direita trecho } \\
\text { superior }-0,64 \text { ha }\end{array}$ & $\begin{array}{l}\text { Plantio de muvuca de sementes com } \\
\text { plantadeira a vácuo; } \\
\text { Plantio de mudas com espaçamento } 5 \\
\text { x } 5 \text { mts; } \\
\text { Plantio de barreiras de crotalária. }\end{array}$ \\
\hline $\mathrm{T} 3$ & $\begin{array}{l}\text { Margem direita, } \\
\text { margem da represa - } \\
2,7 \text { ha }\end{array}$ & $\begin{array}{l}\text { Plantio de muvuca de sementes com } \\
\text { plantadeira a vácuo; } \\
\text { Plantio de mudas com espaçamento } 5 \\
\text { x } 5 \mathrm{mts} \text {. }\end{array}$ \\
\hline $\mathrm{T} 4$ & $\begin{array}{l}\text { Margem direita trecho } \\
\text { inferior }-1,08 \text { ha }\end{array}$ & $\begin{array}{l}\text { Plantio de muvuca de sementes com } \\
\text { plantadeira a vácuo. }\end{array}$ \\
\hline T5 & $\begin{array}{l}\text { Margem esquerda da } \\
\text { lagoa }-0,98 \text { ha }\end{array}$ & $\begin{array}{l}\text { Semeadura da muvuca de sementes } \\
\text { com distribuidor de calcário e adubos } \\
\text { utilizados na agricultura de precisão; }\end{array}$ \\
\hline
\end{tabular}

Quadro 1 - Tratamentos utilizados no PRAD da cabeceira do rio São Lourenço (CHECOLI, 2012).

Fonte: Dados de pesquisa.

As mudas foram doadas pela Prefeitura Municipal de Campo Verde. As sementes foram adquiridas do projeto Rede de Sementes do Xingu, com sede no município de Canarana, Mato Grosso (Quadro 2). Além das espécies listadas abaixo, também foram introduzidas nos tratamentos sementes de Crotalaria juncea, Crotalaria ochroleuca, Cajanus cajan e Canavalia ensiformis, características de rápido crescimento, contribuindo com aumento da massa vegetal e fixação de nitrogênio. 
Técnicas de nucleação como estratégia...

\begin{tabular}{|c|c|}
\hline Espécies plantadas em mudas & Espécies plantadas em sementes \\
\hline Samanea saman & Plathypodium elegans \\
\hline Ingá edulis & Anadenanthera falcata \\
\hline Tabebuia aurea & Myracrodruon urundeuva \\
\hline Tabebuia spp. & Dipterix alata \\
\hline Ingá marginata & Anacardium nanum \\
\hline Enterolobium contortisiliqum & Macherium sp. \\
\hline Tabebuia alba & Terminalia argêntea \\
\hline Cariniana rubra & Jacaranda cuspidifolia \\
\hline Genipa american & Sclerolobium paniculatum \\
\hline Sterculia chicha & Dimorphan dramollis \\
\hline Tamarindus indica & Cecropia pachystachya \\
\hline Myracrodruon urundeuva & Enterolobium schomburgkii \\
\hline Anadenanthera macrocarpa & Samanea tubulosa \\
\hline Buchenavia capitata & Peltogyne confertiflora \\
\hline Colubrina glandulosa & Solanum excelsum \\
\hline Psidium guajava & Buchenavia capitata \\
\hline Ceiba eriantus & Guazuma ulmifolia \\
\hline Ficus catappifolia & Bauhinia sp. \\
\hline Tilisia esculenta & Copaifera langsdorfii \\
\hline \multirow[t]{6}{*}{ Spondia dulcis } & Apeibati bourbou \\
\hline & Enterolobium contortisiliqum \\
\hline & Plathymenia reticulata \\
\hline & Sterculia estriata \\
\hline & Canavalia ensiformes \\
\hline & Cajanus cajan \\
\hline
\end{tabular}

Quadro 2 - Espécies utilizadas no plantio (mudas e sementes) (CHECOLI, 2012). Fonte: Dados de pesquisa. 
As atividades em campo foram realizadas nos meses de julho e dezembro de 2011, e em setembro de 2012, totalizando três coletas. O trabalho de campo foi realizado por uma equipe formada por estudantes, professores e auxiliares, num total de quatro pessoas.

O tratamento 1 (T1) manteve-se isolado de animais por meio de cercas de arames, permitindo a regeneração natural. Nos demais tratamentos $-2,3$, 4 e 5 (T2, T3, T4, T5) - houve, em cada um deles, a seleção aleatória de três parcelas permanentes de estudo, medindo $81 \mathrm{~m} 2(9 \times 9 \mathrm{~m})$, totalizando 12 parcelas (Figura 2).

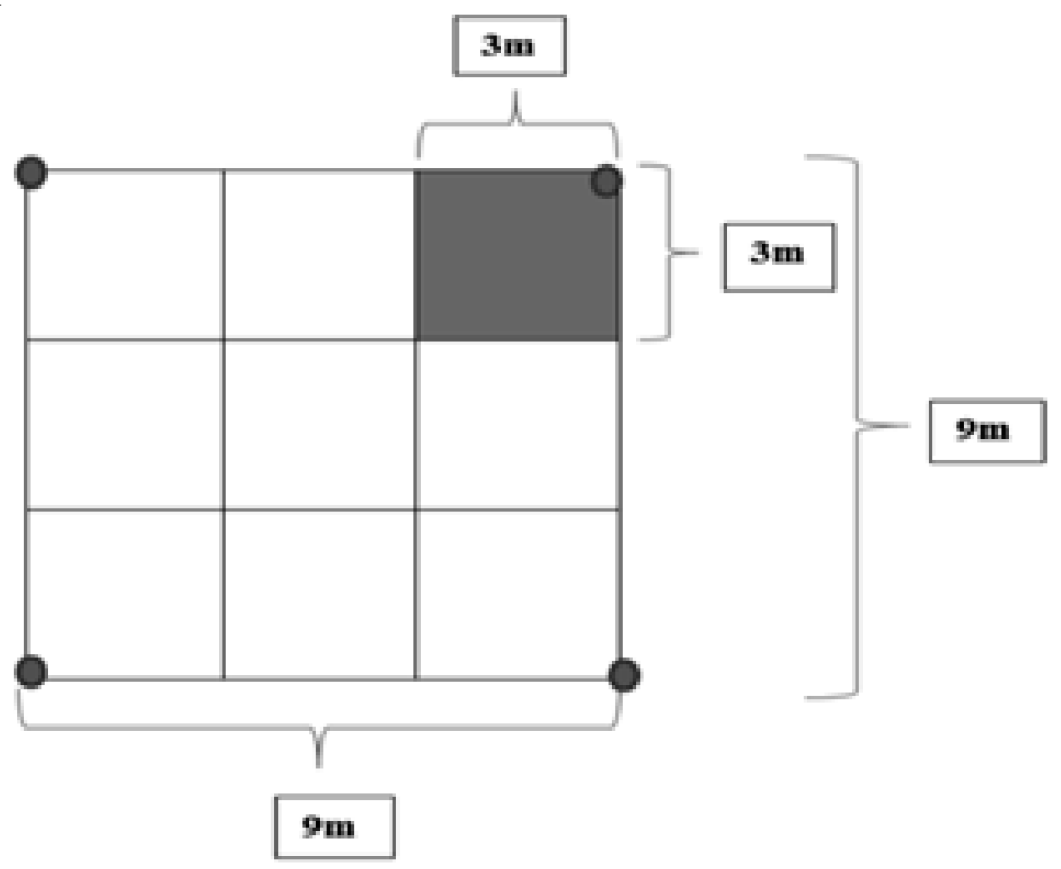

Figura 2 - Esquema das parcelas subdivididas em quadrantes.

Fonte: Dados de pesquisa.

Todas as atividades foram realizadas com a consulta de referencias bibliográficas e in loco, por meio da anotação, observação e registro fotográfico. A metodologia utilizada na avaliação e monitoramento das espécies inoculadas, plantadas e espontâneas, é apontada por Ceconi (2007), considerando prioritariamente a riqueza, a densidade, a abundância de espécies, a cobertura vegetal do solo, retorno da fauna, formação de microclimas, núcleos vegetacionais, etc., sendo realizados por meio da implantação de parcelas permanentes de avaliação. $\mathrm{O}$ acompanhamento e a identificação dos bioindicadores da recuperação ambiental ocorreramem todos os tratamentos emestudo, seguindo as metodologias descritas por Santos et al.,
(2001), Reis et al., (2003), Ruiz-Jaen e Aide (2005) e Balensiefer (2012).

\section{Resultados E Discussões}

No acompanhamento e avaliação de ecossistemas em recuperação foram utilizados os indicadores ecológicos (DALE; BEYLER, 2001), pois é de reconhecimento mundial a utilização do biomonitoramento como ferramenta na avaliação da qualidade ambiental (LIMA et al., 2005). Ocorre a avaliação dos seres que habitama área de estudo, o que possibilita a avaliação da qualidade ambiental local. A vantagem do uso de bioindicadores sobre os métodos convencionais de avaliação da qualidade ambiental está em seu baixo 
custo, podendo, inclusive, serem utilizados para a avaliação cumulativa de eventos ocorridos num determinado período de tempo, resgatando umhistórico ambiental não passível de detecção ou medição por outros métodos (CETESB, 2013).

$\mathrm{O}$ etnoconhecimento, explanado por Reis et al. (1999), confirmou que algumas plantas, de forma especial, quando em frutificação, "exercem uma grande atração sobre a fauna, pois elas atraem os animais que vêm se alimentar de seus frutos e aqueles que se utilizam para predarem outros animais". Plantas estas conhecidas como bagueiras, ou seja, espécies capazes de atrair uma fauna diversificada devem ser utilizadas como "promotoras de encontros interespecíficos dentro de áreas degradadas, exercendo, no contexto aqui tratado, o papel de nucleadoras".

A produção de serapilheira, material de origem vegetal, como folhas, flores, frutos, cascas e sementes, são indicadores biológicos de recuperação da área degradada, representados nas figuras abaixo, por frutos de lobeira e pelo feijão-de-porco (Figuras 3 e 4 ).
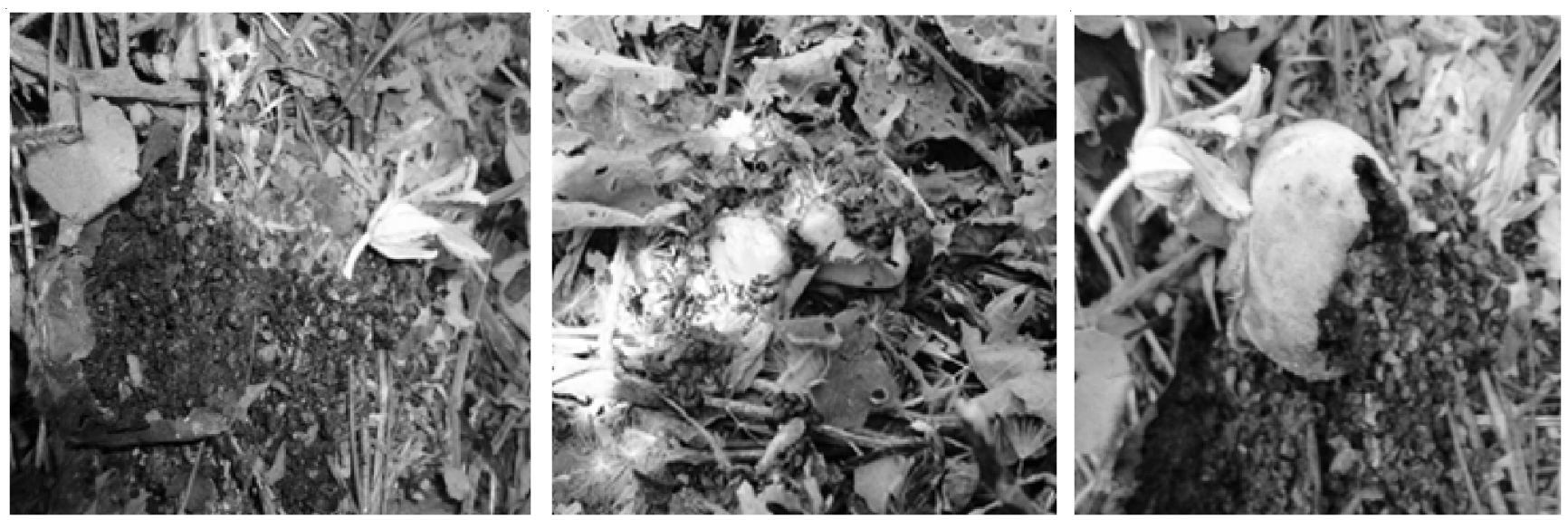

Figura 3 - Flores e frutos de lobeira em decomposição.

Fonte: Dados de pesquisa.
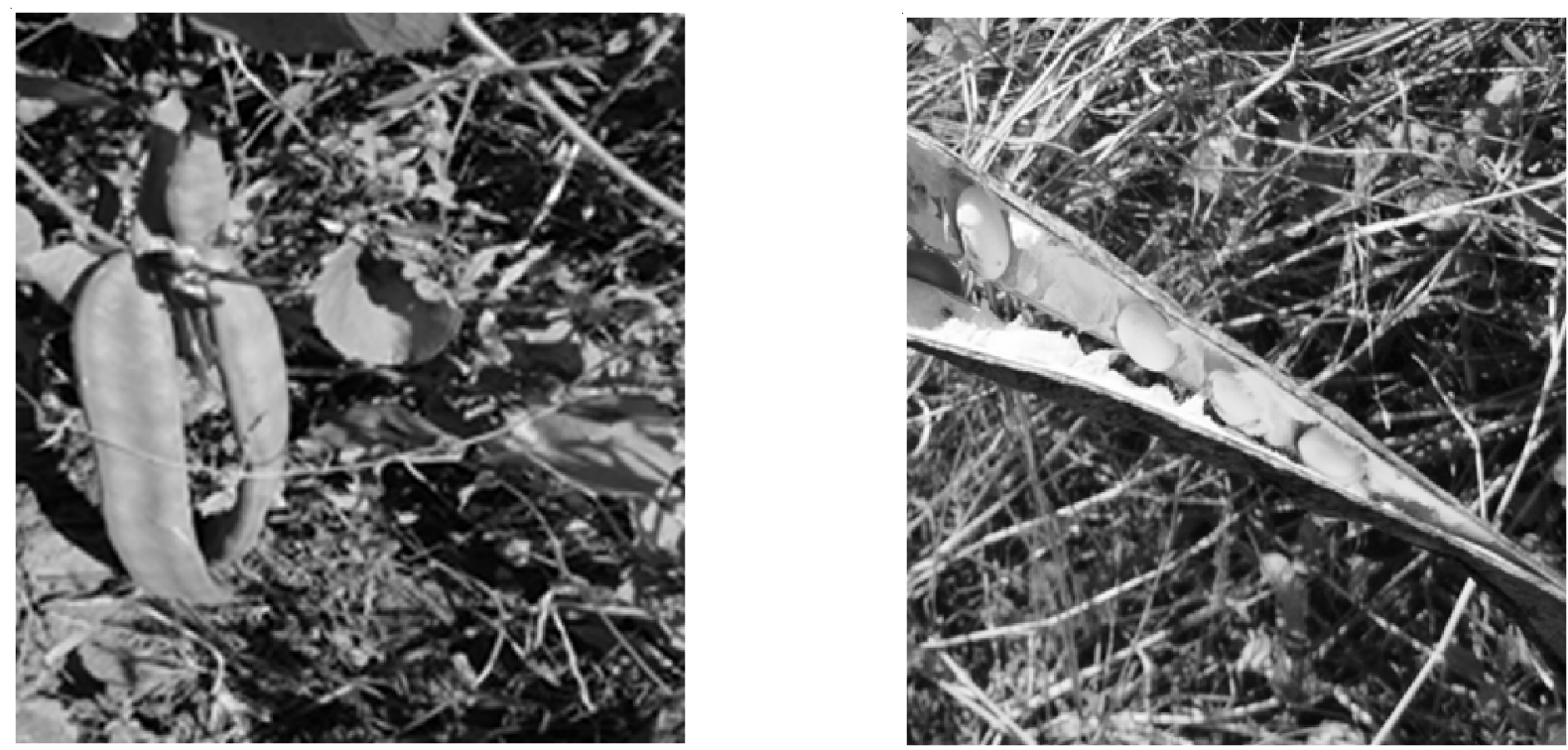

Figura 4 - Frutos de Feijão-de-porco.

Fonte: Dados de pesquisa. 
Os materiais orgânicos auxiliam a liberação de nitrogênio e outros nutrientes, que atuam como condicionadores das propriedades físicas, físicoquímicas e biológicas do solo. Além de estimular a atividade biológica e a produção de enzimas (fosfatase, urease, protease), assim como diminuir a densidade do solo, prevenir contra a erosão e defesa contra patógenos (SANTOS et al., 2001). Na unidade demonstrativa de estudo, a cobertura vegetal e produção de serapilheira foi satisfatória. Conforme observado abaixo (Figura 5), a biomassa cobre quase que totalmente o solo. A quantidade de matéria orgânica na camada superficial do solo é um indicador que representa o processo de ciclagem de nutrientes, especialmente através da decomposição da serapilheira, um importantíssimo indicador de "função ecológica" (SMA, 2009).
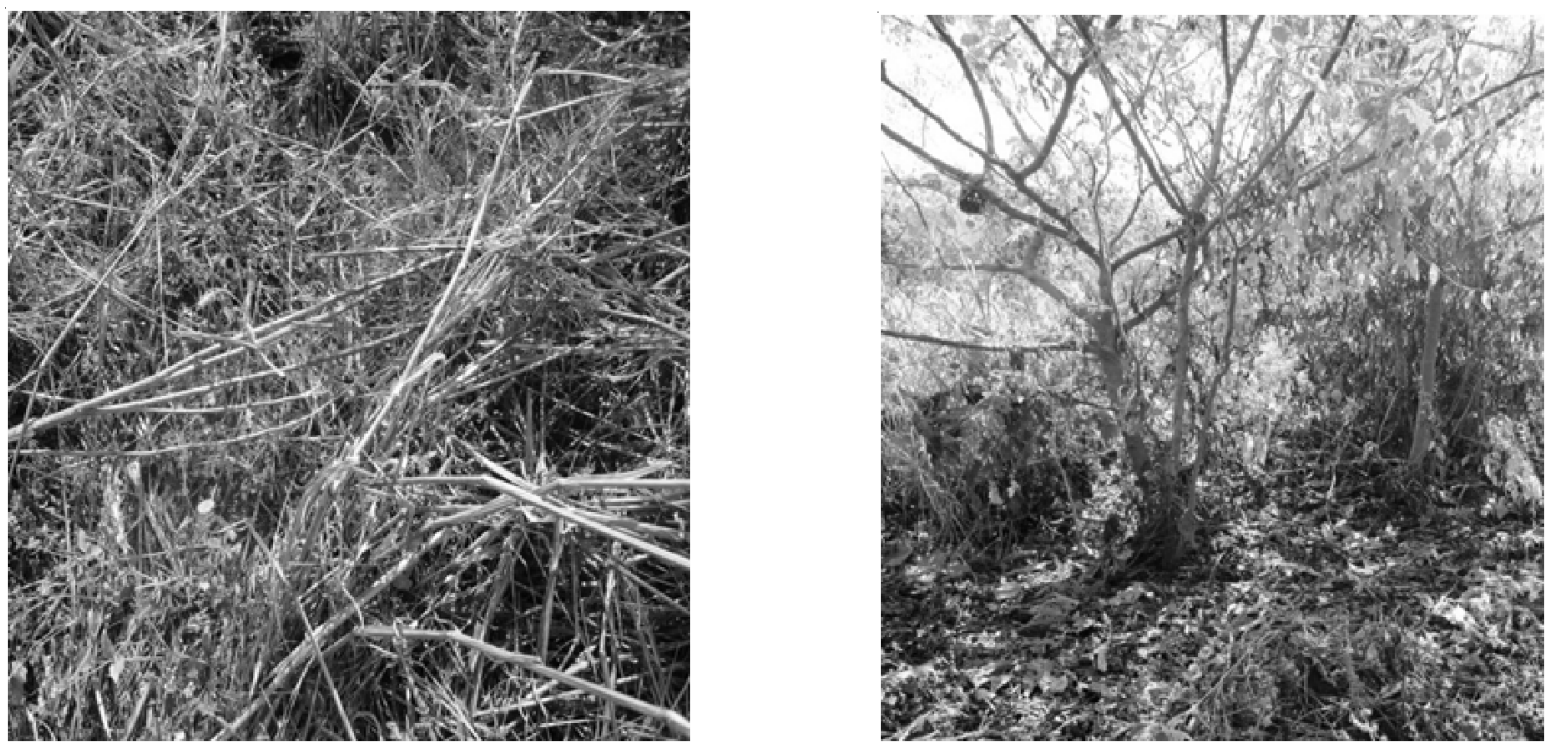

Figura 5 - Presença de necromassa recobrindo o solo no interior do tratamento três.

Fonte: Dados de pesquisa.

A cobertura vegetal, conforme Santos et al. (2001), mantém uma maior umidade do solo e protege do impacto das chuvas, evitando a erosão. A decomposição da biomassa vegetal aumenta o conteúdo de matéria orgânica, reduzindo perdas de nutrientes e favorecendo a atividade biológica do solo. Ocorre ainda uma liberação lenta de nutrientes que são utilizados pelas culturas de forma gradativa e adequada. As raízes das plantas exploram diferentes profundidades e proporcionam uma maior presença de macroporos, evitando o escorrimento superficial. Além de favorecer a germinação das sementes.

Contudo, pesquisas realizadas na mesma área de estudo, no ano de 2011, por Cândido et al. (2012), verificaram que a densidade média de indivíduos macroinvertebrados presentes no solo "foi maior na serapilheira da mata ciliar ( 272 ind. $/ \mathrm{m}^{2}$ ) em relação à serapilheira da unidade demonstrativa de restauração ecológica $\left(7,11 \mathrm{ind} . / \mathrm{m}^{2}\right)$ ". Isso pode ser explicado pelo fato de o acúmulo de serapilheira acompanhar fases da sucessão ecológica, ou seja, há relação direta entre a produção de serapilheira e o desenvolvimento da vegetação.

A distribuição de necromassa e a quantidade de serapilheira podem predizer o estado de conservação dos ambientes. A sucessão de organismos da meso e macrofauna presentes nas etapas de recuperação, como populações de insetos como formigas, cupins, abelhas e besouros, são bons bioindicadores ecológicos terrestres da recuperação de áreas degradadas (SAUTTER, 1998). 
Balensiefer (2012) afirma que a camada de detritos no solo e a existência de gramíneas e arbustos podem ser atrativas de aves e de animais em busca de alimentos. Consequentemente, podem trazer frutos e sementes, eliminando-os junto às fezes nesses locais, auxiliando no processo de semeadura. Posteriormente, dependendo da espécie e das condições do local onde a semente foi depositada, poderá ocorrer a germinação e desenvolvimento, desencadeando o processo de

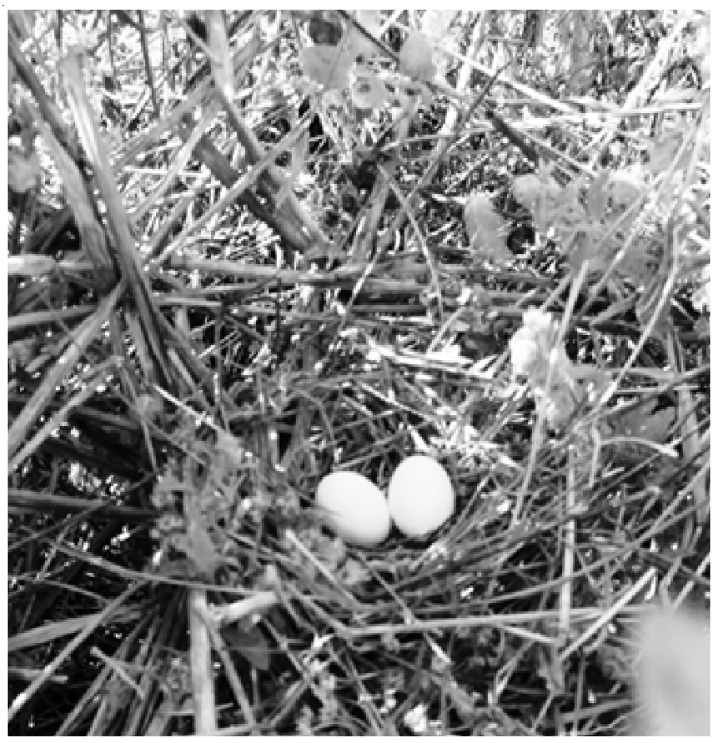

regeneração natural.

Durante o levantamento de campo foram observados indícios de retorno da fauna ao ambiente em recuperação, como ovos de pássaros, abrigos de animais como o tatu (Figura 6Ae B), também répteis como lagartos e cobras (Figura $7 \mathrm{~A}$ ), além de pegadas de mamíferos (Figura 7 B). Bem como a diversidade de "grupos-chave", como abelhas, aves e borboletas, no auxílio e propulsão das atividades ecossistêmicas.

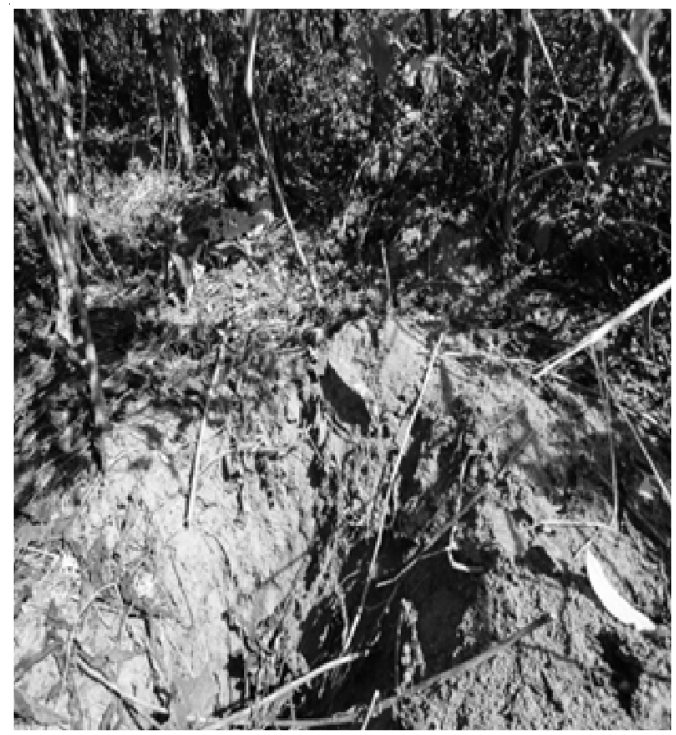

Figura 6 - A) Ovos de pássaros. B) Abrigo de animais. Fonte: Dados de pesquisa.

O retorno da fauna é de extrema importância para acelerar o processo de recuperação ambiental. Desse modo, há estudos que demonstram a estreita correlação existente entre atributos estruturais da vegetação e a abundância e diversidade de fauna (RUIZ-JAEN;
AIDE, 2005). Segundo Balensiefer (2012), a presença de animais na área assume papel relevante pela sua interação com as plantas no contexto. Pássaros e roedores, além do vento, despontam como agentes da dispersão de sementes. 

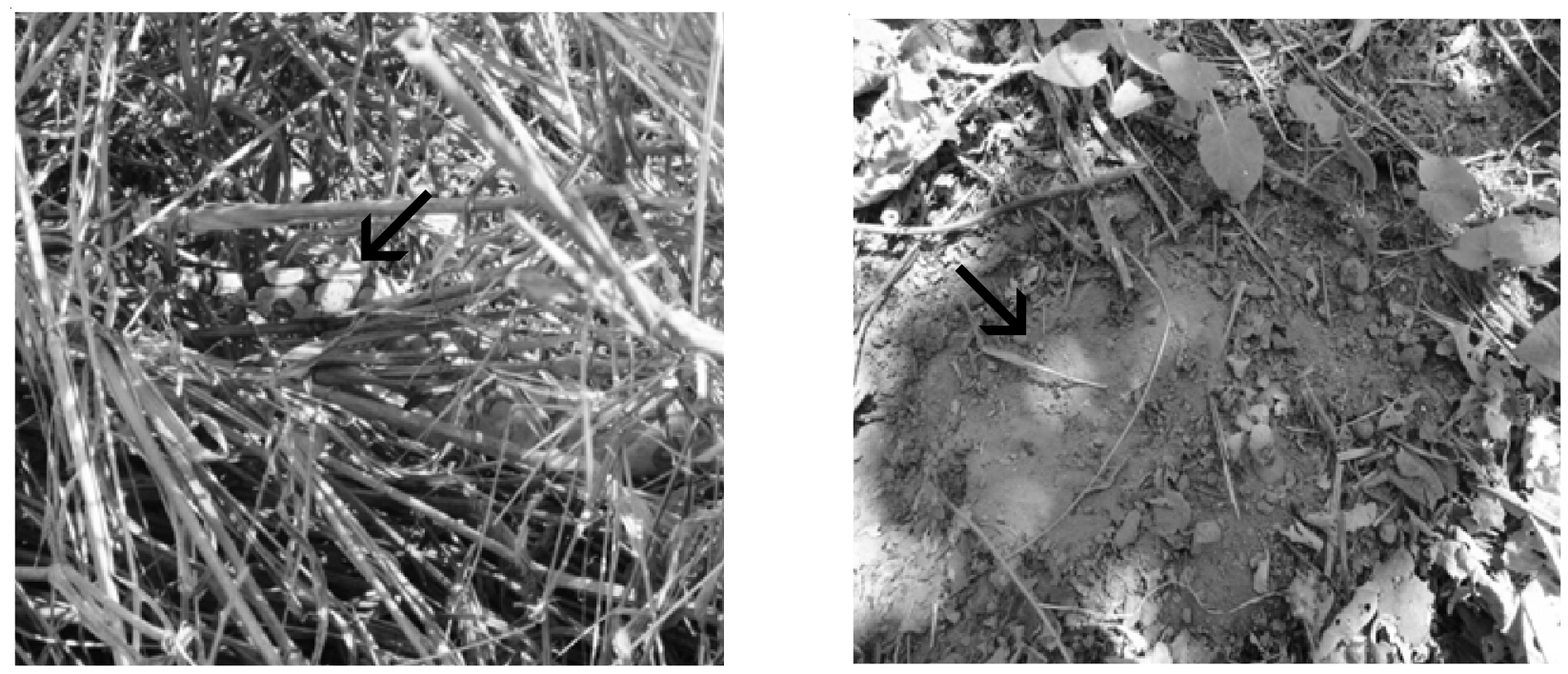

Figura 7 -A) Réptil. B) Pegada de mamífero.

Fonte: Dados de pesquisa.

Após dois anos de desenvolvimento do PRAD, foi possível encontrar na área de pesquisa, inúmeros ambientes que formam um microclima (Figura 8), ou seja, já fornecem abrigo para os animais; aumento da taxa de evapotranspiração; diminuição da temperatura e aumento da umidade atmosférica. Assim, a arborização oferece um microclima mais estável, com maior sombreamento e unidade, além de variedades e disponibilidade de itens alimentares.

Farias et al. (2012), por meio de pesquisas realizadas na mesma área de estudo no ano de 2011, coletaram dados de umidade relativa do ar e temperatura do are do solo, em ambientes diferentes, na área em recuperação e na mata ciliar. No local em recuperação, a "temperatura média do ar foi de $30,27^{\circ} \mathrm{Ce}$, na mata ciliar, foi de $28,10^{\circ} \mathrm{C}$; em relação à temperatura média do solo, na área em recuperação foi de $21,95^{\circ} \mathrm{C}$, e de $20,95^{\circ} \mathrm{C}$ na mata ciliar". Quanto à umidade relativa do ar, "a média na área em recuperação foi de $66 \%$ e $72,83 \%$ na mata ciliar".

Portanto, a mata ciliar obteve os melhores resultados das variáveis avaliadas em relação à área em recuperação. Com isso se espera que, em um futuro próximo, o ambiente formado pelas espécies plantadas nas unidades demonstrativas apresente também bons resultados quanto à temperatura do ar e do solo, bem como a umidade relativa do ar, ou seja, objetiva-se a restauração ecológica do ambiente. 


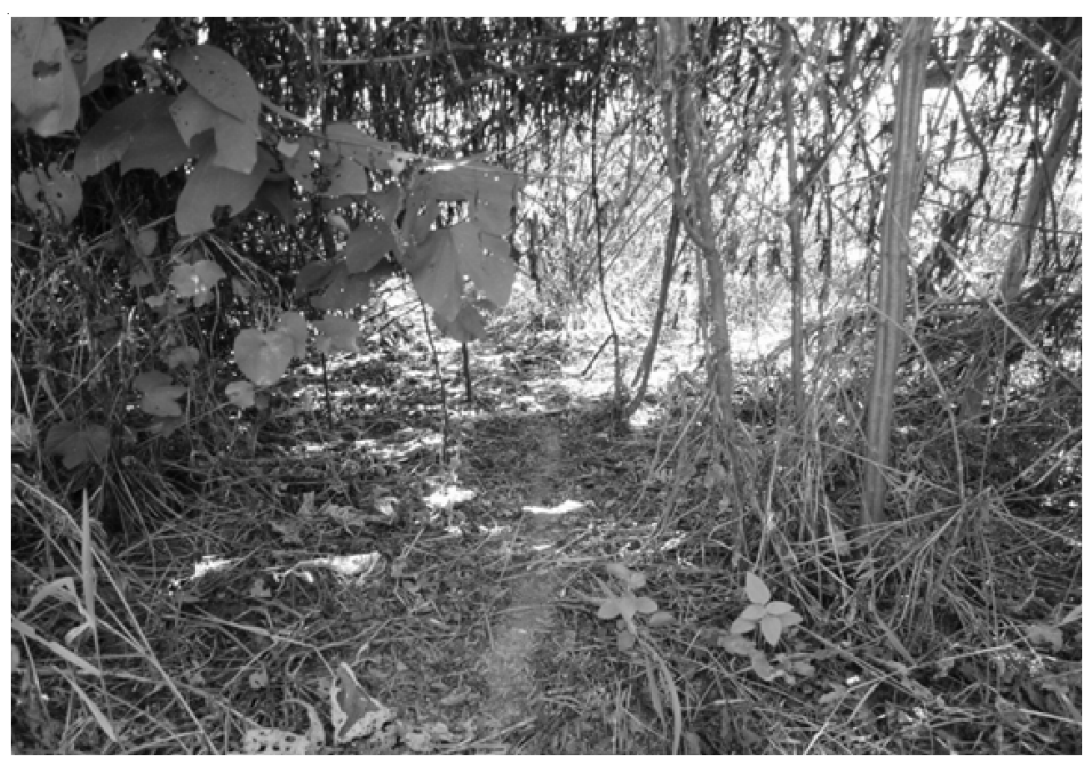

Figura 8 - Figura 8 - Cobertura vegetal presente no tratamento três que propicia sombreamento e microclima para o estabelecimento de espécies de sombra.

Fonte: Dados de pesquisa.

A retirada dos agentes de perturbação das áreas (acesso de animais e cultivo agrícola) favoreceu e aumentou sua capacidade de regeneração. A manutenção da vegetação para os processos ecológicos é importante na ciclagem de nutrientes, assim como na preservação dos recursos hídricos. A proteção do solo é um dos resultados, assim como o retorno da fauna. Outro importante e essencial resultado positivo foi a consciência e a mobilização dos produtores rurais, proprietários da área de estudo.

Para Reis et al., (2003), a nucleação é eficiente na implementação da sucessão dentro de áreas degradadas, pois ela "promove o retorno da biodiversidade à paisagem sob as condições microclimáticas locais".

\section{CONSIDERaÇões Finais}

A fundamental importância da água na manutenção da vida é o principal motivador para o estudo, planejamento e gerenciamento dos recursos hídricos, e nisto se inclui a preservação da vegetação ciliar dos corpos d'água.

Portanto, a pesquisa realizada é extremamente motivadora em recuperar ambientes degradados, pois a mesma se mostrou eficiente no seu objetivo principal, impulsionando a sucessão vegetal, bem como aproximando o local das suas características físicas e biológicas originais.

\section{Agradecimentos}

Ao Programa de Pós Graduação em Recursos Hídricos (PPGRH), pela oportunidade. Á Universidade Federal de Mato Grosso (UFMT), pela logística, e à Coordenação de Aperfeiçoamento de Pessoal de Nível Superior (CAPES), pelas bolsas de estudo concedidas.

\section{REFERÊNCIAS}

\section{AGÊNCIA NACIONAL DE ÁGUAS. Bacias}

Hidrográficas. 2009. Disponível em: http://

www2.ana.gov.br/Paginas/portais/bacias, acesso em: 17 maio 2011.

AZEVEDO, A. A.; SAITO, C. H. O perfil dos desmatamentos em Mato Grosso, após implementação do licenciamento ambiental em 
propriedades rurais. Cerne, Lavras, v.19, n., p.111-122, jan./mar. 2013.

BALENSIEFER, M. Recuperação de Áreas Degradadas. UFPR. Curitiba, 2012.

CAMPO VERDE. Geografia. Campo Verde: Prefeitura Municipal de Campo Verde. 2012. Disponível em: http://informe.campoverde.mt.gov.br/ Acesso em: 19 maio 2011.

CÂNDIDO, A.K.A.A.; SILVA, N.M.; BARBOSA, D.S.; FARIAS L.N.; PIETRO-SOUZA, W. Fauna edáfica como bioindicadores de qualidade ambiental na nascente do rio São Lourenço, Campo VerdeMT, Brasil. Engenharia Ambiental, Espírito Santo do Pinhal, v. 9, n. 1, p. 067-082, jan. /mar.2012.•.

CASARA K.P. Dinâmica ambiental de pesticidas em área de nascente degradada do rio São Lourenço/Mato Grosso. Dissertação (mestrado em Recursos Hídricos/UFMT). Cuiabá, 2011.

CECONI, D. E. Dossiê de Ambiência e Transição Agroecológica no Manejo da Microbacia Hidrográfica do Lajeado Biguá, 2007. Dissertação (Mestrado em Ciência do Solo) Santa Maria, UFSM. 2007.

CHECOLI, C.H.B. Gestão participativa da microbacia hidrográfica da cabeceira do Rio São Lourenço: definição e implantação de diferentes tecnologias para realização do PRAD, Campo Verde, 2012. Dissertação (Mestrado em Recursos Hídricos/UFMT). Cuiabá-MT. 2012.

CETESB. Companhia Ambiental do estado de São Paulo. Bioindicadores. Disponível em: http:// www.cetesb.sp.gov.br/solo/informacoes-Básicas/ Vegetação/8-Bioindicadores, acesso em: 04 jun.2013.

DALE, V.H.; BEYELER, S.C. Challenges in the development and use of ecological indicators. Ecological Indicators, 1, p. 3-10, 2001.

FARIAS, L. N.; SILVA, N. M.; BARBOSA, D. S; CÂNDIDO, A. K. A. A. PIETRO-SOUZA, W. Parâmetros microclimáticos e atributos químicos e físicos do solo em área de preservação permanente situada na cabeceira do rio São Lourenço, Campo Verde-MT. Engenharia Ambiental, Espírito Santo do Pinhal, v. 9, n. 1, p. 83-99, jan. /mar. 2012.

\section{INSTITUTO BRASILEIRO DE GEOGRAFIA E ESTATÍSTICA. Censo 2011. Brasília. 2011.}

LIMA, J. S. et. al. Programa de biomonitoramento da qualidade do ar da cidade do Salvador proposta e resultados preliminares. In: CONGRESSO BRASILEIRO DE ENGENHARIA SANITÁRIA E AMBIENTAL, 23, 2005, Campo Grande. Anais.,. Campo Grande, 2005.

LIMA, J. A. Morfopedologia aplicada à interpretação da dinâmica hídrica de duas nascentes na alta bacia do rio São Lourenço. Dissertação (Mestrado em Recursos Hídricos/ UFMT). Cuiabá-MT. 2012.

MARTINS, S. V. Recuperação de Áreas Degradadas: ações emáreas de preservação permanente, voçorocas, taludes rodoviários e de mineração. Aprenda fácil. Viçosa/MG. 2010.

PIETRO-SOUZA, W.; CÂNDIDO, A. K. A. A.; FARIAS, L. N.; SILVA, N. M.; BARBOSA, D. S. Produção de necromassa e de serapilheira em Área de Preservação Permanente pertencente ao rio São Lourenço, Campo Verde-MT. Engenharia Ambiental, Espírito Santo do Pinhal, v.9, n.1, p. 47-66, 2012.

POSSAVATZ, J. Contaminação por pesticidas em águas superficiais, subterrâneas e pluviais em área de nascente do rio São Lourenço-MT. 
Monografia (Bacharelado em Química/UFMT). Cuiabá, 2010.

REIS, A., ZAMBONIN, R. M.; NAKAZONO, E. $M$. Recuperação de áreas florestais degradadas utilizando a sucessãoe as interações planta-animal. Série Cadernos da Biosfera 14. Conselho Nacional da Reserva da Biosfera da Mata Attântica. Governo do Estado de São Paulo. São Paulo, 42 p., 1999.

REIS, A.; BECHARA, F. C.; ESPINDOLA, M. B.; VIEIRA, N. K.; SOUZA, L. L. Restauração de áreas degradadas: a nucleação como base para incrementar os processos sucessionais. Natureza $\boldsymbol{\&}$ Conservação, Curitiba, v. 1, n. 1, p. 28-36, 2003.

RUIZ-JAEN, M.C.; AIDE, M. Restoration success: how is it being measured? Restoration Ecology, 13, p. 569-577, 2005.

SALOMÃO, F.X.T.; VECCHIATO, A. B.; WEBER, O.L.S.; DORES, E.F.G.C.; SPADOTTO, C.A.; PINTO, A. A. Estudo do Comportamento Físico Hídrico de Solos da Região Sudeste de Mato Grosso Visando a Proteção dos Recursos Hídricos.
In: Simpósio de Recursos Hídricos do Norte e Centro Oeste, 1, 2007.

SANTOS, R.H.S.; SILVA, F.; CASALI, V.W.D.; CONDE, A.R. Efeito residual da adubação com composto orgânico sobre o crescimento e produção de alface. Pesquisa Agropecuária Brasileira, v.36, n.11, p.1395-1398, 2001.

\section{SAUTTER, K.D. Meso e macrofauna na} recuperação de solos degradados. Viçosa, UFV, 1998.

SECRETARIADE ESTADO DE MEIO AMBIENTE (SEMA). Plano Estadual de Recursos Hídricos do estado de Mato Grosso. KCM Editora. Cuiabá, 2009.

SECRETARIADE ESTADO DE MEIO AMBIENTE (SEMA). 2011. Disponível em: www.sema.mt.gov.br, acesso em 04 jun. 2013.

SILVEIRA, F. A. M. Abelhas brasileiras: sistemática e identificação. Belo Horizonte: Composição e Arte, 2002. 253p.

ReCEBIDO EM 3/7/2013

ACEITO EM 4/11/2013 